\title{
Technical and Economical Performances of Photovoltaic Generation Façades
}

\author{
Massimo Caruso, Rosario Miceli, Pietro Romano, Giuseppe Schettino and Fabio Viola \\ Department of Energy, Information engineering and Mathematical models, University of Palermo, Viale delle Scienze, \\ Building nr.9, 90128, Palermo, Italy \\ (massimo.caruso16@unipa.it, rosario.miceli@unipa.it, pietro.romano@unipa.it, giuseppe.schettino@unipa.it, fabio.viola@unipa.it) \\ `Corresponding Author: Fabio Viola; Viale delle Scienze, edificio 9, Parco d’Orleans, fabio.viola@unipa.it \\ phone: +3909132860253
}

Received: 12.06.2018 Accepted:25.06.2018

\begin{abstract}
This paper presents an experimental investigation on the economical contribution given by a vertical-mounted PV system, which is placed on a façade of a building, replacing the traditional windows or glass-cement walls with active elements. The purpose of this work is to perform a comparison between the performances of next-generation systems and the traditional ones. Several systems have been tested and compared, obtaining promising results both in terms of efficiency and fill factor.
\end{abstract}

Keywords PV modules, DSSC, thin film silicon, building integrated photovoltaic.

\section{Introduction}

Nowadays, more of $40 \%$ of the world Carbon Dioxide (CO2) emissions are caused by the air conditioning, the heating and electric power systems of buildings. Thus, the optimization of their performances and the reduction of building consumptions can significantly contribute to increase the sustainability of our planet, trying to fit the International Energy Agency (IEA) requirements, with a perspective of a $80 \%$ of reduction by 2050 regarding the global emissions [1].

In this context, it is important to provide a refurbishment of the existing buildings, which can be generally obtained by means of two different methodologies:

- Passive methods, consisting of a reduction of the demand for both heating and cooling;

- Active methods, concerning the installation of lowenergy equipment/technologies and the adoption of renewable energy generation systems.

With regards to the latest, a significant reduction of both heat and cooling losses could be provided by replacing the traditional windows with next-generation photovoltaic walls
[2-4]. Furthermore, the new technology of PV systems, namely third generation and realized with DSSC (dyesensitized solar cell) [5], is designed to be more suitable for architectural integration [6]. In addition, due to their bifacial feature, the adoption of DSSC cells can efficiently convert the light coming from both the indoor and the outdoor environments. Therefore, a possible application of these next-generation panels is to replace the glass of windows, reducing the silicon in thin layers, so that the transparency of the support is guaranteed.

This paper presents an experimental investigation and performance comparison of two technologies, DSSC and thin-film silicon, when adopted as photovoltaic façades. The advantages of such technologies are evaluated in terms of efficiency, costs and fill factor. The paper in [12] describes the evaluation of the performances of a DSSC system by thickness variation of nanocrystalline $\mathrm{TiO} 2$ for $8.13,16.5$, 26.7 and $32.2 \mu \mathrm{m}$.

More in detail, the work is structured as follows: 
- Section 2 reports an historical description and the actual scenario regarding the building-integrated photovoltaic technology.

- Section 3 describes the PV structures adopted as façades.

- Section 4 describes the experimental set-up for the measurement of the main electrical quantities involved in the system.

- Section 5 compares the performances obtained by the PV technologies

Section 6 draws the technical and economical conclusions on the advantages of using PV systems as façades.

\section{The Development of Solar Technology in BIPV}

Building integrated photovoltaic (BIPV) systems play a fundamental role in the reduction of pollutants: they are able to produce energy where it is needed, playing an essential part in the development of zero-energy buildings. New features such as colors and aesthetic design, flexible and transparent shells, are concurring to reduce the barriers posed against the spread of BIPV systems.

BIPVs employ PV materials in order to substitute the conventional bulk building materials, which are part of the building covers, i.e. the roofs, walls and windows. In such a way, BIPV are considered as a functional part of the building structure, due to their dual role: envelope structure and power generation. Therefore, they are increasingly integrated into the design of the building in the first stages, no longer in later phases of refurbishing. The BIPV system serves as building envelope material and power generator simultaneously and it has a great advantage compared to non-integrated PV systems, because there is neither need for allocation of additional space nor reduction and adaption in building added photovoltaic (BAPV).

The next subsections present both the evolution of photovoltaic technologies and the diffusion in architectural integration.

\subsection{First Generation of $P V$ in $B I P V$}

Single junction solar cells based on silicon wafers made the first generation of PV cell technology. The panel is massive, thick, the color, always the same, announces the operation of a new technology, which does not make compromise with the external environment and aesthetic integration. The first generation of PV systems in BIPV (sometimes BAPV) mounts directly onto the roof of building and sometimes in the façade, as shown figure 1.

Rigid structures characterize the first generation PV, mainly crystalline silicon (c-Si) PV cells are employed, whose main parameters are hereinafter reported:

- $\quad$ Thicknesses high (about 0.2-0.5 mm);

- Efficiencies between 10 and 16\%;

- Efficiency guaranteed twenty to thirty years;
- Consolidated know-how (on the market since the '70s);

- Current costs: approx. 3000-4500 €/ kWp installed.

Sometimes the high cost of the panels forces economics in integration solutions, so reducing the aesthetic and the integration.

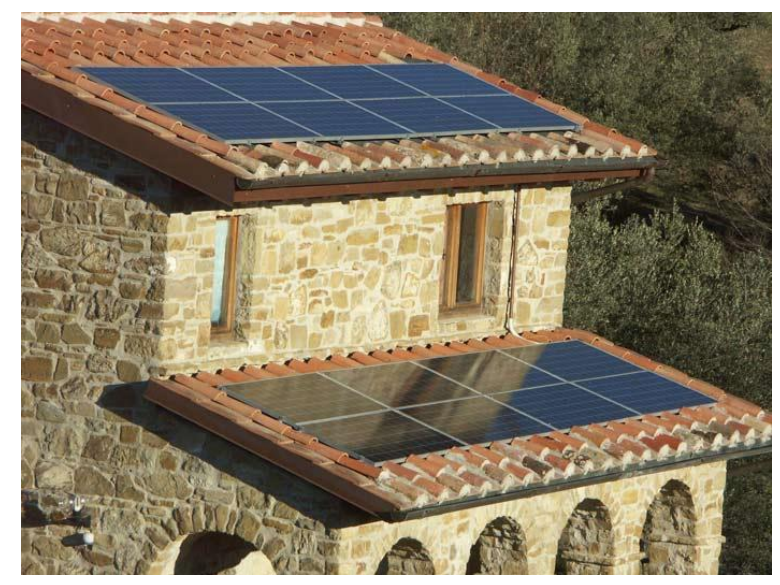

(a)

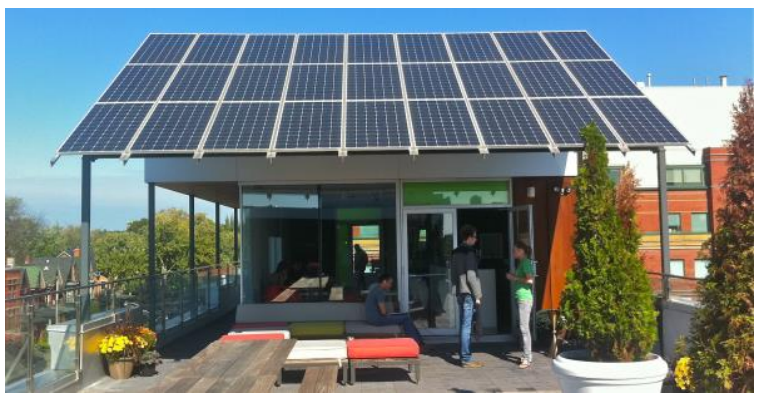

(b)

Fig. 1. First examples of BIPV on exiting building (a), on a new construction.

In order to reduce the costs, the polycrystalline (poly$\mathrm{Si}$ ) technology was developed. Poly-silicon is produced by employing an upgraded metallurgical-grade silicon, using metallurgical instead of chemical purification processes. Due to the non-uniform tonality, poly-Si modules are not well suited to architectural integration.

\subsection{Second Generation of $P V$ in $B I P V$}

As mentioned before, single junction devices drive the second generation of photovoltaic technologies, but with the aim of using less active material to equate or approximate the efficiencies of first generation.

Second-generation photovoltaic solar cells use amorphous (a-Si), Cadmium telluride/cadmium sulphide (CdTe/CdS), Copper indium gallium diselenide (CIGS) or polycrystalline-Si (p-Si) deposited on low-cost substrates, such as glass.

These technologies benefit from the fact that CdTe, CIS and a-Si absorb the solar spectrum better than C-Si and poly- 
$\mathrm{Si}$, allowing a reduction of active material, whose main parameters are here reported:

- Low thicknesses (about 10-100 $\mu \mathrm{m}$ ), possible flexible panels;

- $\quad$ Efficiencies between 6 and 10\%;

- Guaranteed efficiency 15-20 years;

- Know-how in consolidation (first products commercials for just over fifteen years).

Figure 2 shows how the second PV generation intervention has contributed to the decrease in costs as pieces increase.

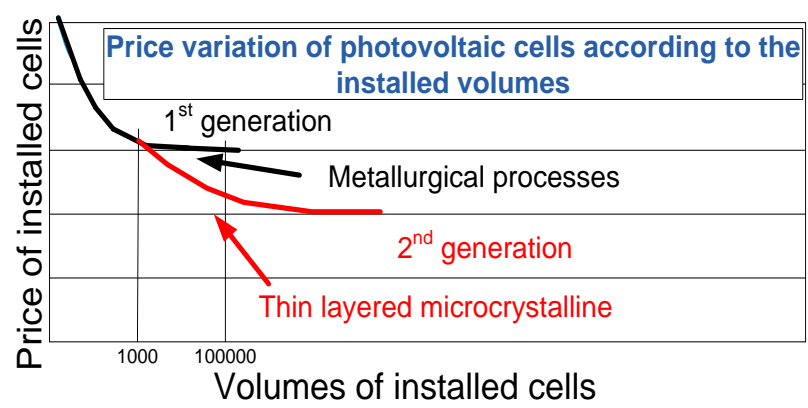

Fig. 2. Reduction of cost for the second generation of PV: metallurgical processes are cheaper and allow the obtainment of more elements, thin layered microcrystalline semiconductor materials deposition modules make the system cheaper.

A thin-film of amorphous silicon solar PV cells is obtained by deploying several layers of photovoltaic solar cell materials onto a substrate. A thin film can also be deposited at very low temperatures, as low as $75^{\circ} \mathrm{C}$, which allows the deposition on plastic support in order to realize curved structures, such as the one shown in figure 3 .

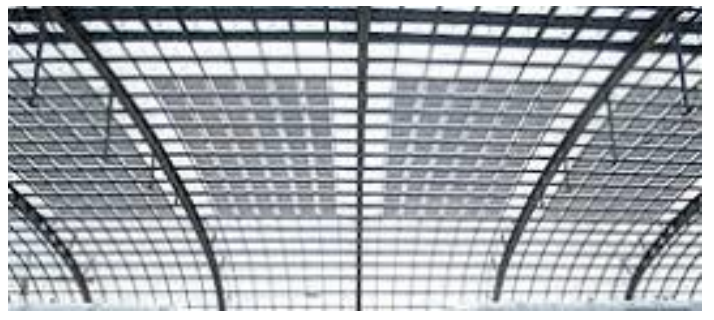

Fig. 3. Structure obtained with second generation of PV.

\subsection{Third Generation of $P V$ in $B I P V$}

Third-generation photovoltaic cells inherited from the second one the deposition methods and the thin film, trying the reduction of costs by employing low cost materials and by increasing the surface of active material. The aim is to achieve high-efficiency of second-generation, but employing more and more materials that are both nontoxic and not limited in abundance. The related main features can be summarized as follows:
- Theoretically achievable efficiencies: $25 \%$ and above;

- Current phase: study of models and operational research;

- Materials presumably used: inorganic

Figure 4 shows the objectives of the third generation of PV: in order to increase the diffusion of generation systems, to rethink each surface as an improved surface, or to generate energy or to manage thermal transmission, the price reduction should be able to increase the occupied area.

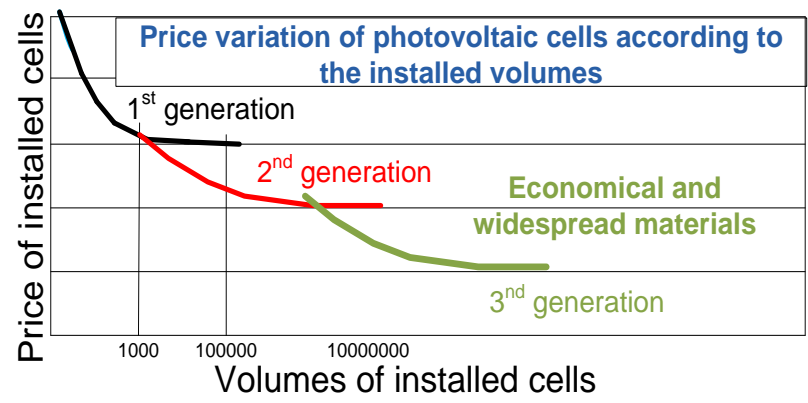

Fig. 4. Reduction of cost for the third generation of PV.

\subsubsection{Dye-sensitized Solar Cells (DSSC)}

The dye-sensitized solar cell (DSSC) was originally invented in 1988 by Brian O'Regan and Michael Gratzel at UC Berkeley [5]. It is a low-cost solar cell belonging to the group of thin film solar cells.

The DSSC has a number of attractive features, such as:

- it is semi-flexible and semi-transparent offering a variety of new uses, ignored by rigid support systems;

- most of the materials used are low-cost and abundant in nature;

- density of short circuit current Jsc is about 20 $\mathrm{mA} / \mathrm{cm} 2$;

- $\quad$ open circuit voltage Voc is about $0.7 \mathrm{~V}$;

- $\quad$ efficiency $\eta$ is $10-12 \%$;

- $\quad$ stability problems at high temperatures (above $70^{\circ}$ C), but stable up to $60-65^{\circ} \mathrm{C}$

- ideal for low-cost and high-volume production;

- $\quad$ stability problems related to the use of liquid redox mediators, need to find solid mediators;

- $\quad$ efficiencies expected in 5-10 years over 20\%;

- good performances even with diffused light;

- $\quad$ it is necessary to develop less expensive and less polluting dyes than the present ones (based on heavy metals). 
Figure 5 represents the working scheme of a DSSC.

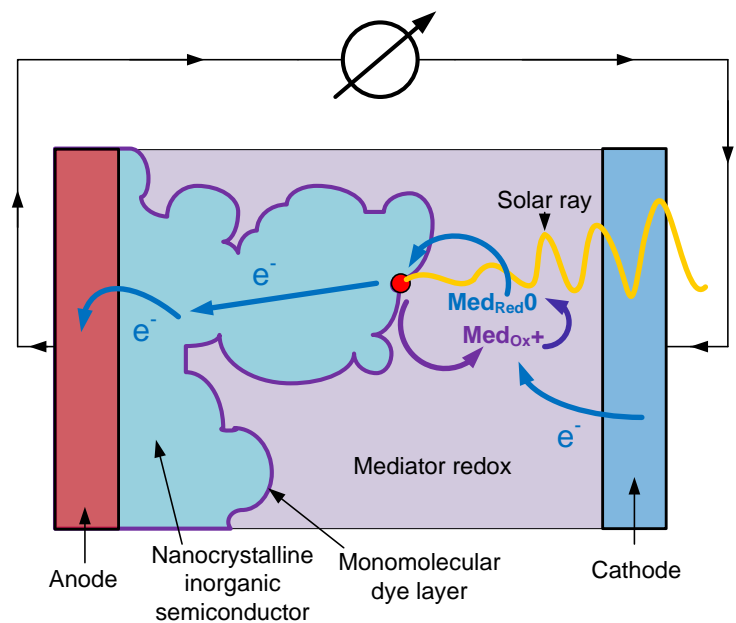

Fig. 5. Representation of the operation of a DSSC.

1) An inorganic semiconductor nanocrystalline is deposited on a transparent electrode and coated with one monomolecular dye layer organic. All elements are immersed in one liquid electrolyte, in which one redox mediator is dissolved.

2) An organic dye, hit by a solar ray, produces an excited state (electron + lacuna); the electron is injected into the conduction band of the inorganic semiconductor, while the lacuna remains on the dye, which oxidizes (loses an electron)

3) The redox mediator provides the electron missing the dye, it is oxidized to its time.

4) The electron previously injected in the semiconductor reaches the anode and passes into the electric circuit to feed load.

5) An electron flows from the cathode in the electrolyte to reduce the oxidized mediator, thus closing the circuit.

DSSCs can vary the dye and make different colouring, to ensure greater architectural integration

\subsubsection{BIPV Structures}

Third generation of PV allows to create different products: foil, tile, module and solar glazing. Foil products show good features, they are flexible and lightweight, which allows the employment on roofs where excessive weights cannot be used.

Tiles can cover the whole roof or selected parts of it, in order to acquire special aesthetics; the old tile geometry can be reproduced to grant a pleasant retrofit of historical buildings. The third generation of PV module embraces the possibility to wear also different colors.

PV cell glazing products offer an unlimited assortment of choices for windows, facades, glassed and roofs; with different colors and transparencies, the aesthetics objectives can be joined without reducing the production. The solar PV cell glazing modules diffuse sunlight and offer protection from elements as a normal window. Figure 6 shows the different products.

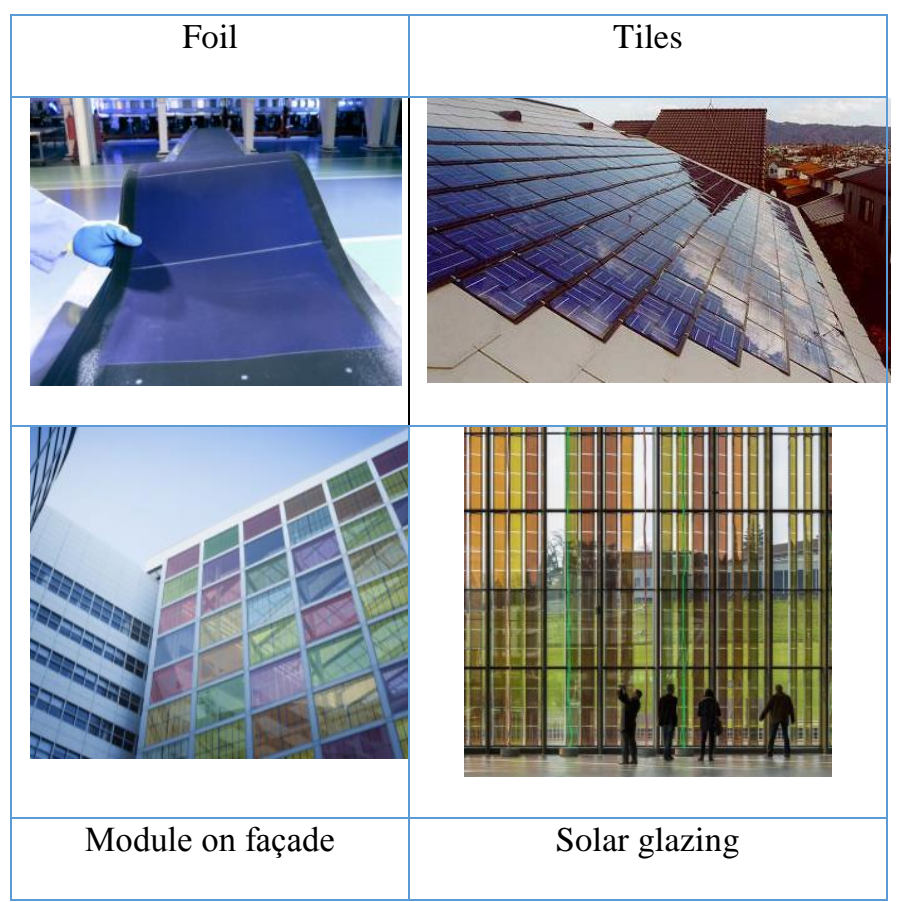

Fig. 6. BIPV third generation products.

\section{Vertical Wall Structures}

It has to be highlighted that the purpose of adopting PV windows can be summarized in three main objectives: production of electrical energy, transmission of light in the building and regulation of the heat transmission.

Semi-transparent modules are integrated inside a glass shell for the obtainment of shading solutions and the transparency must be balanced in order to maximize simultaneously the energy savings and the generation of electricity [9-11].

Three generation systems are used and compared, as shown in Fig. 7, which depicts the PV systems during their installation at the University of Palermo. More in detail, 8 series-connected DSSC modules $(30 \times 30 \mathrm{~cm}$, Daunia Solar Cell Inc.), consisting of a wide striped and narrow lined design, are used for the glass panel assembly (see Fig.8).

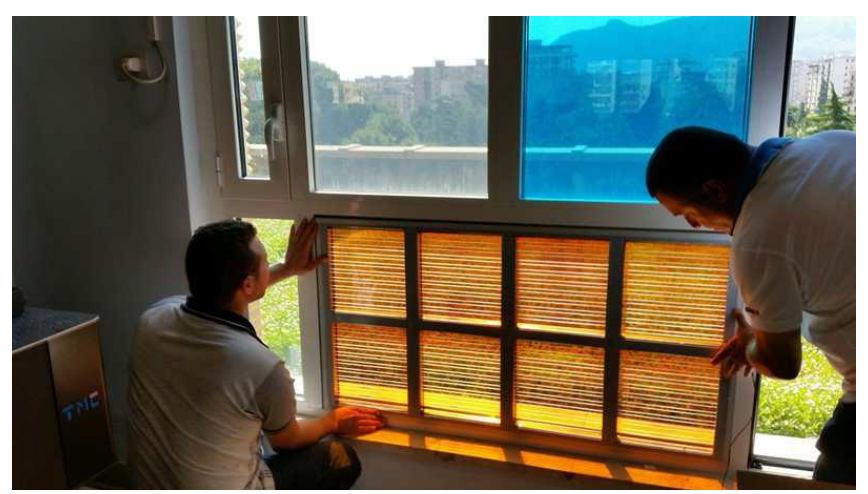

Fig. 7. Photovoltaic generating façade set-up. 


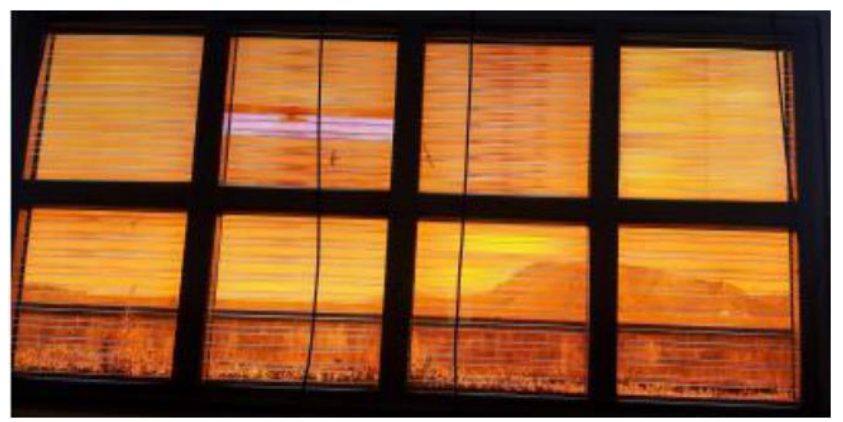

Fig. 8. DSSC PV wall system, made by Daunia solar cell.

As shown in Fig. 9, the two other systems are cells composed by amorphous silicon thin film (Onix Solar), with the same degree of transparency.

All the proposed structures are subjected to shade during the afternoon, in which they receive only scattered light.
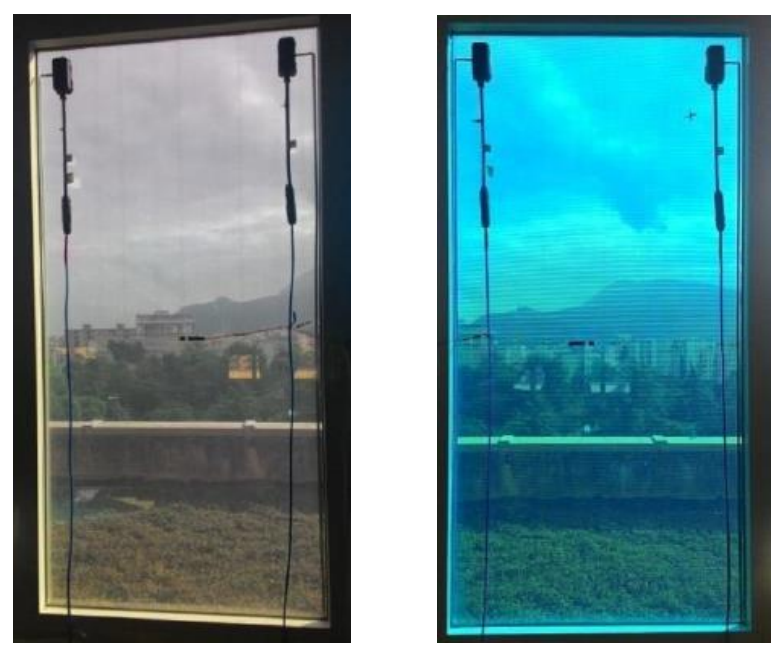

Fig. 9. Amorphous silicon PV walls system: Grey cell (left), Blue cell (right), made by Onix solar.

The open circuit voltages of the DDSC and the A-Si PV windows are equal to 23 and $48 \mathrm{~V}$, respectively. These values are suitable for DC loads, but far from the ones used in domestic DC/AC converters.

With regards to architectonical integration, a DSSC integrated within a vertical glass block is considered [13], which is shown in Fig. 10. This structure can be imagined as the composition of 2 two different shells of transparent glass, which are joined together by the use of an opaque frame. The glass block guarantees transparency to radiation and ensures the mechanical function of the system with flat surfaces.

The adoption of such structure decreases the cell performances, due to the fact that the radiation effect on the DSSC surface is decreased by the presence of the glass. Moreover, the opaque element projects a shadow on the DSSC, limiting its performances as well.

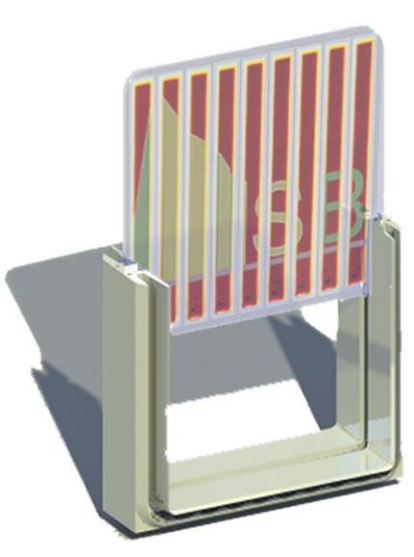

a)

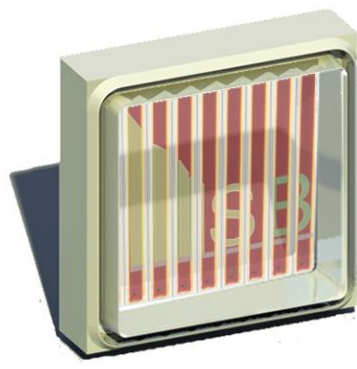

c)

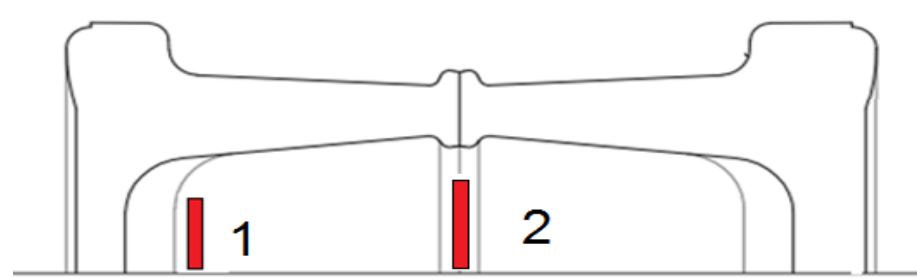

e)

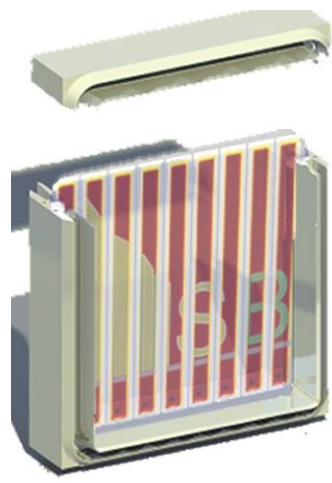

b)

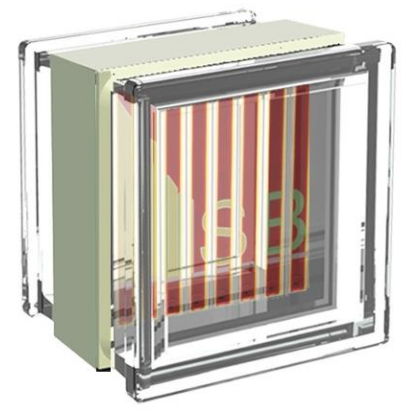

d)
Fig. 10. a)-d) Structure of the PV DSSC generating glass block: the opaque edging frame, two glass shell structure and the colored DSSC [13]. e) section of the glass block in which the DSSC is red coloured: 1 internal placement on the surface, 2 in the middle section.

\section{Measurement Setup}

The experimental test bench has been set-up in order to measure the performances of the proposed systems simultaneously. The measurement set-up for the acquisition of both voltages and currents is depicted schematically in Fig. 11. It mainly consists of: 
- A low-noise/high-precision Source-Meter (Keithley 2420), whose function is to ensure a stable DC supply.

- A LabView interface, connected to the SourceMeter.

- A switch, used for triggering the measurement one by one for the three different windows.

- An Arduino microcontroller, used for the on/off control commands of the switch and which communicates with the Labiview interface.

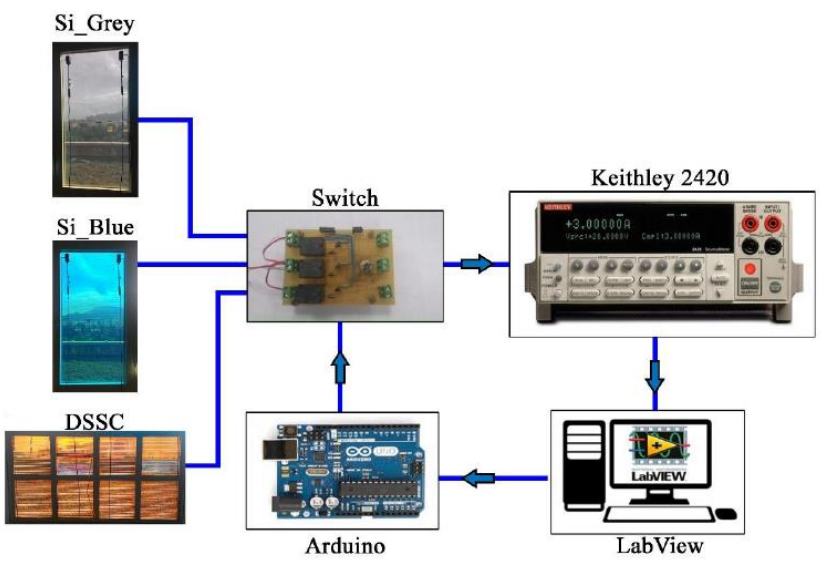

Fig. 11. Measurement setup.

The measurement of the open-circuit voltage for all the three structures is provided by the Source-Meter. The data are acquired by the Labview interface, which controls a current cycle measure that starts from the open circuit voltage increased by 0.5 volts, up to a voltage of -0.5 volts. This range is divided into 100 parts, so that for each module a set of measures developed on 100 acquisitions can be acquired.

The settling down of the modules is ensured by delaying the acquisition system. This automated system has been adopted for the modules characterization over several months. In addition, other important parameters, such as irradiation, room temperature and glass surface temperature were also sampled by means of the Arduino board.

\subsection{Glass Block Performance Characterization}

It has been already highlighted that the glass structure reduces the DSSC performances and shades the module during the day. By referring to Fig. 12, which depicts the sensors located at the glass block surface, these performance reduction can be evaluated by considering 15 different positions including the vertical edges (the 16th position is considered as reference value and it is outside of the structure).

The distribution of daylight in the glass block was performed by considering four exposures: south, north, east and west [14]. For instance, the distribution of the performance reduction for south and north exposure are depicted in Fig. 13.

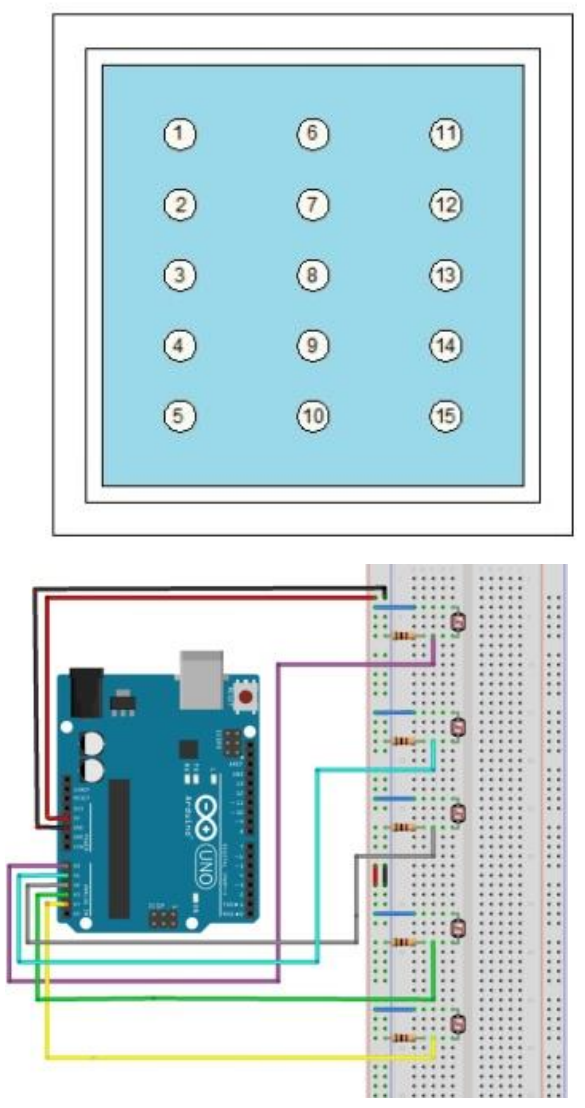

Fig. 12. The 15 positions in which the sensors were placed inside the glass block, and a partially set-up of the arduino microcontroller.

There are clearer and darker areas. By reducing the DSSC performances in lighter areas is just appreciable (if the DSSC is placed close to the inner surface), while in the darker areas, there has been a reduction in yields of $10-20 \%$ (especially if the DSSC was kept in the middle of the shell).
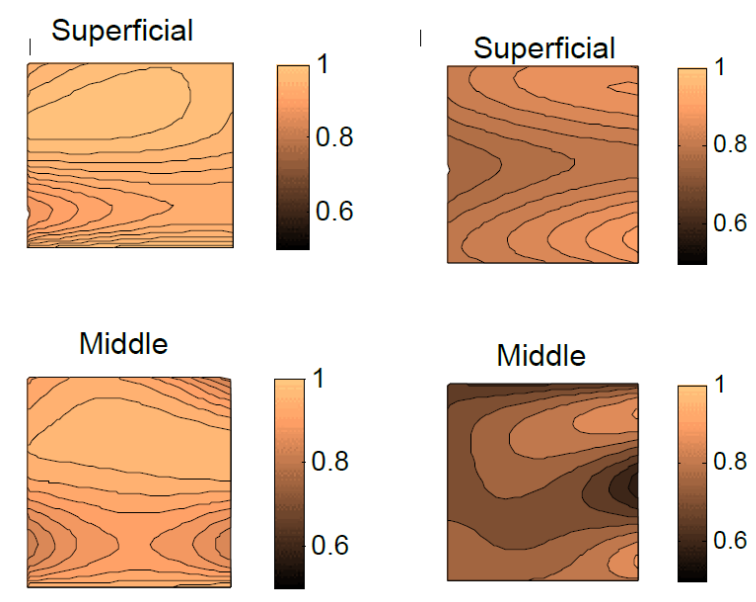

Fig. 13. Superfical shaded areas of glass block. On the left the southern exposure, on the right the northward. 


\section{Analysis of the PV Wall Performances}

The data acquired from the test bench described in Section 4 have been processed and the I-V and P-V characteristics for each of the proposed system have been determined and plotted in Figs 14-19. These data consider measurements in different days (three during the morning and three during the afternoon) with different levels of solar radiation. Since the proposed windows are exposed towards east, the results show higher production during the first hours of the related day.

The trends refer to a sunny day of July with a good solar radiation in order to obtain a high power output and reliable current-voltage curves. An initial value of solar irradiation of $715 \mathrm{~W} / \mathrm{m} 2$ and a final value of $68 \mathrm{~W} / \mathrm{m} 2$ were detected.

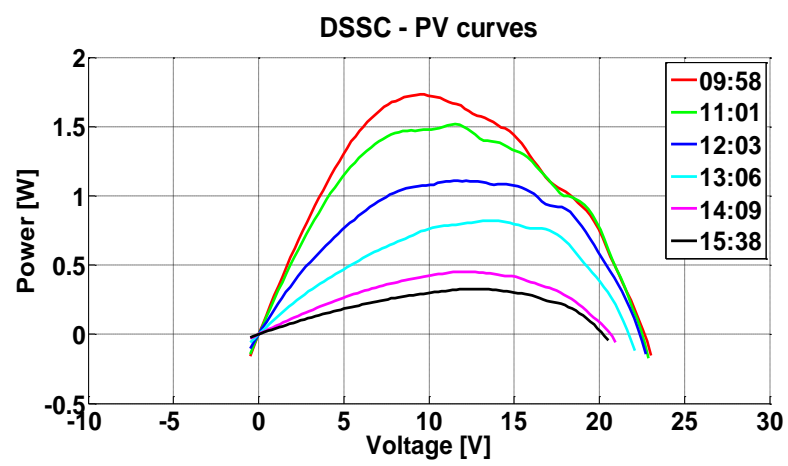

Fig. 14. Power-voltage profiles of the DSSC cell at various levels of irradiance.

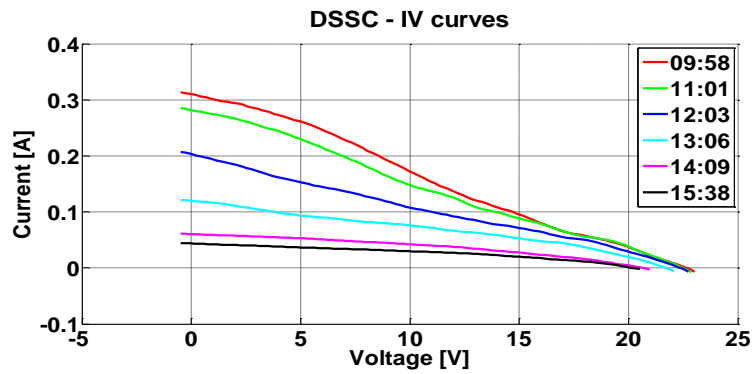

Fig. 15. Current-voltage profiles of the DSSC cell at various levels of irradiance.

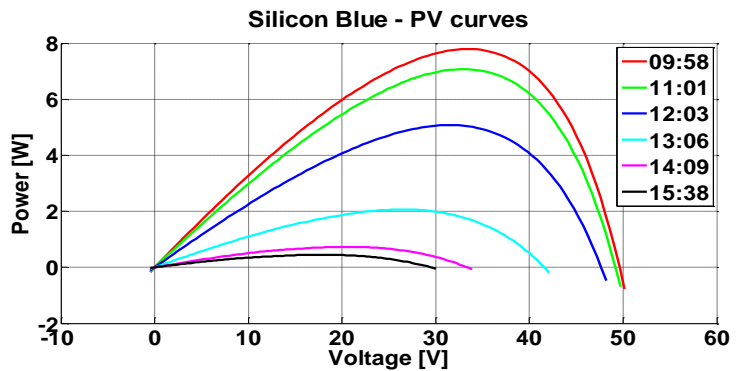

Fig. 16. Power-voltage profiles of the blue silicon cell at various levels of irradiance.

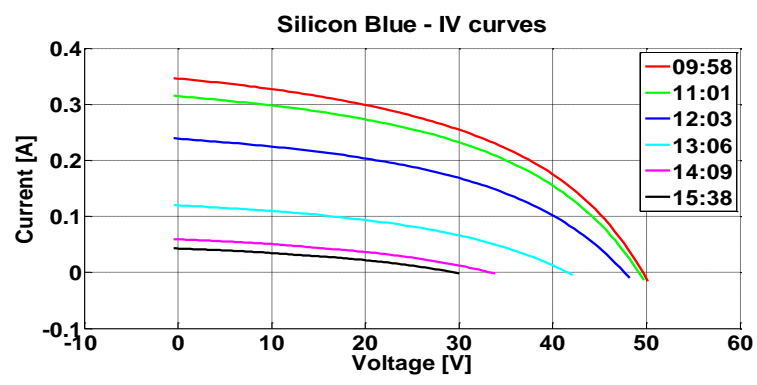

Fig. 17. Current-voltage profiles of the blue silicon cell at various levels of irradiance.

The comparison of the previously reported trends leads to the result that the DSSC module produces less power than the silicon cells. Furthermore, the last ones have a higher open circuit voltage, allowing a better interfacing with power electronics systems, which require adequate voltage levels.

The a-Si generation system has an open circuit voltage of about 50 volts with high irradiation conditions, an adequate value for DC power supply, compared to the 23 volts of the DSSC generation system, which will require boost converters.

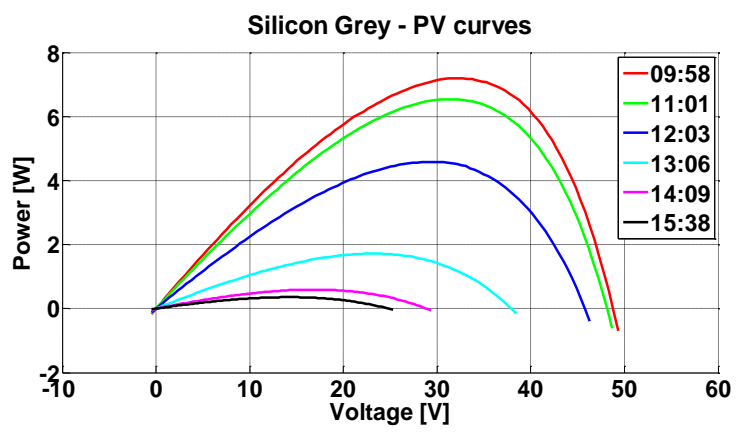

Fig. 18. Power-voltage profiles of the grey silicon cell at various levels of irradiance.

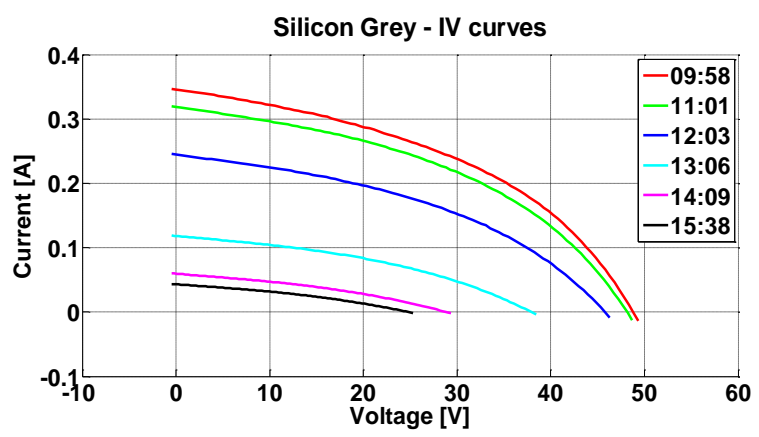

Fig. 19. Current-voltage profiles of the grey silicon cell at various levels of irradiance. 


\subsection{Comparison of the Results}

In order to determine the performances of the three generation systems, a set of measurements to evaluate the produced power, fill factor and efficiency trends for each PV technology, have been carried out.

The produced power has been obtained from current and voltage measurements, subsequently determining the daily power profile and extracting the daily value of the maximum produced power. Figure 20 and Figure 21 show the produced power trend in the morning and afternoon for each PV technology. Figure 21 shows that the produced power by the DSSC is lower than the silicon cells during the morning, but has similar values in the afternoon hours.

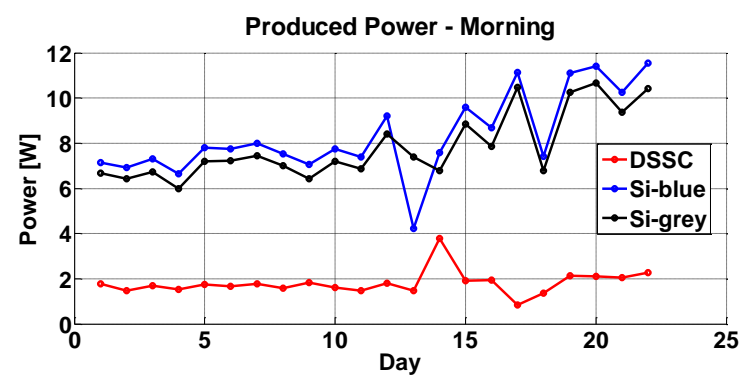

Fig. 20. Produced power profiles in the morning of the three generation systems.

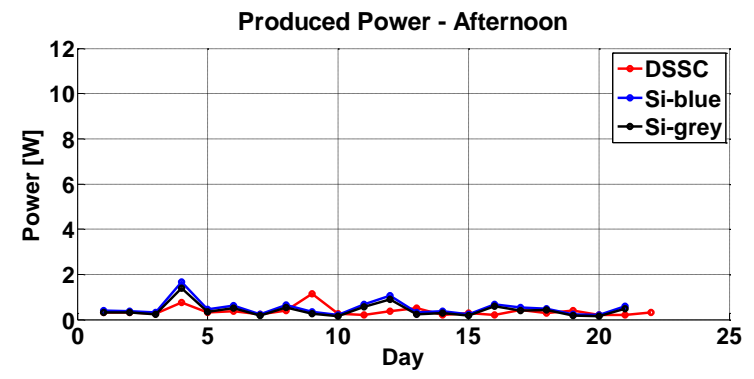

Fig. 21. Produced power profiles in the afternoon of the three generation systems.

The Fill Factor (FF) of a solar cell is essentially a measure of quality of the solar cell. It is calculated by comparing the maximum obtainable power (PM) to the theoretical power that would be output to the product of the open-circuit voltage (Voc) and short-circuit current (Isc):

$$
\mathrm{FF}=\mathrm{P}_{\mathrm{M}} /\left(\mathrm{V}_{\mathrm{oc}} \cdot \mathrm{I}_{\mathrm{sc}}\right)
$$

Figure 22 and Figure 23 show the fill factor profiles in the morning and afternoon of the three generation system.

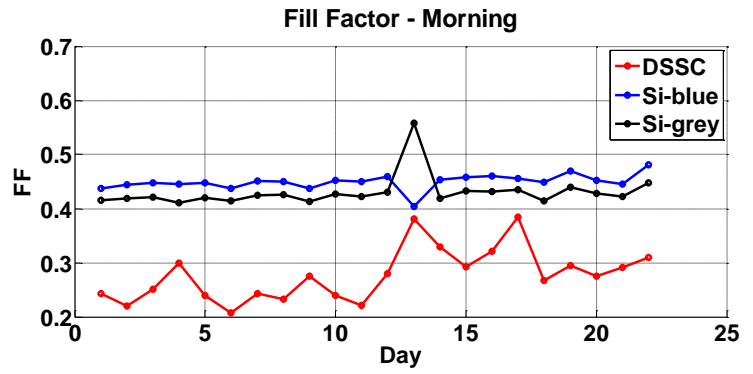

Fig. 22. Fill Factor profiles in the morning of the three generation systems.

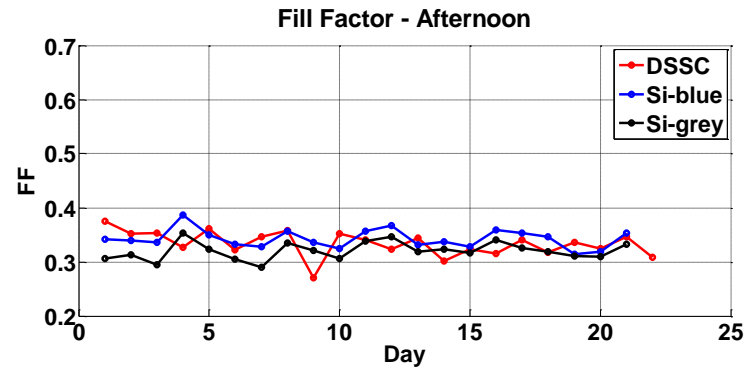

Fig. 23. Fill Factor profiles in the afternoon of the three generation systems.

The efficiency is the ratio between the maximum power (PM) and irradiance power (Pin), evaluated by the product of the total area of the panel $(0,72 \mathrm{~m} 2)$ for the irradiance value (in this case was taken as reference to the irradiance value on vertical panel):

$$
\eta=P_{M} / P_{\text {in }}=F F \cdot\left(V_{\text {oc }} \cdot I_{\text {sc }}\right) / P_{\text {in }}
$$

Figure 24 and Figure 25 show the efficiency profiles in the morning and afternoon of the three generation system.

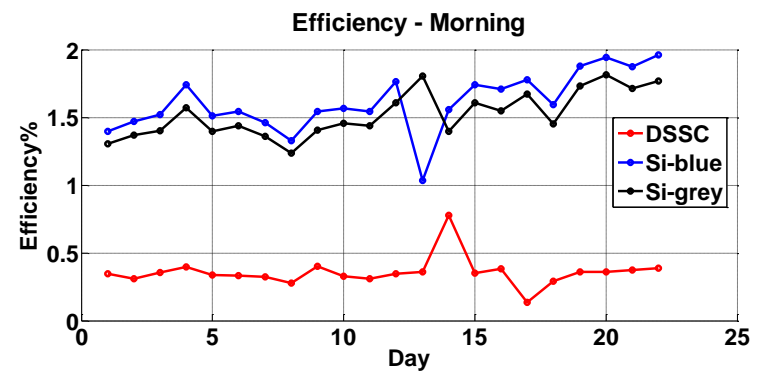

Fig. 24. Efficiency profiles in the morning of the three generation systems.

The efficiency of silicon windows varies, an average of $1.5 \%$ was found in the morning and $1 \%$ in afternoon. 


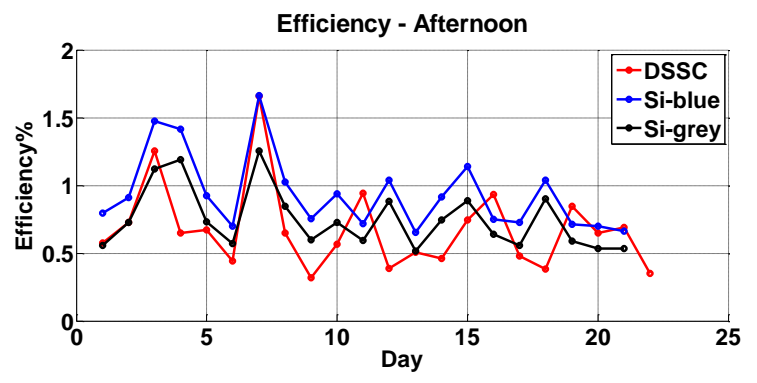

Fig. 25. Efficiency profiles in the afternoon of the three generation systems.

The performance of the DSSC cells improves in diffuse light in the afternoon, compared to direct light in the morning.

The low efficiency value $(1.5 \%)$ of the a-Si is easily explained. A commercial panel of a first or second generation photovoltaic system normally has an efficiency of $10 \%$, corresponding to azimuth inclination; when inclined by $90^{\circ}$ (located on the façade of a building), it reduces its efficiency from its maximum value to a further 0.40 factor [15]. To gain in transparency, active material above the glass holder is progressively reduced; so, the transparency reduce the yield to $1.5 \%$.

Instead, for the DSSC, useful values to compare the evaluated results, without considering the vertical disposition, can be found in the works of Han et al [8], Kwak at al. [16], Peng at al.[17], Wang and Wong [18]. In their recent studies Han found a FF about $70 \%$, Kwak about 63.67, Peng a variable between $55.5 \%$ to 77.7 dependig on the color, Wang and Wong a FF varying from $55.5 \%$ to 73.1 depending on the properties of electrolyte.

Similar performances can be found in [7], in the laboratories of Fraunhofer ISE the FFs and efficiencies of DSSC, a-Si and CIGS (copper indium gallium diselenide) were compared, DSSC again has shown worst performances than a-Si.

Some discussions on the degradation of the DSSC should be addressed, since during the test, the DSSC cells had a progressive color degradation, even becoming transparent in the last period of the measurements. This obvious phenomenon due to the not optimized sealing conditions, in our experiment, does not cause an excessive reduction of the electrical performances of the cells, but only provides an aesthetic alteration. The observed DSSC degradation is not due to a loss of electrolyte outward, but it is due to a "Photo induced Electrophoresis" occurring between adjacent cells due to non-hermetic sealing between the strips. More in detail, the light polarizes PV cells consecutively increasing voltages and if the strip electrolyte comes into contact with the neighbor, it creates a lateral drift and separation of ions I-/ I3-, which results in an electrolyte color change in areas where iodine deficiency is present. Figure 26 shows a comparison of the cells in about four months of measures.
The phenomenon of progressive degradation of DSSCs is not new [19], but in this case to a macroscopic visual degradation does not correspond a degradation of electrical performances. To avoid this phenomenon, different researcher are focusing their efforts on the development of stable electrolytes [18]. A similar alteration of the DSSC has been reported in a very recent paper [8]; the authors discovered a power conversion efficiency reduction about $64 \%$ after 200 hours of exposition. Instead, Kwak. discovered a reduction of efficiency about $73.5 \%$ after 1000 hours.

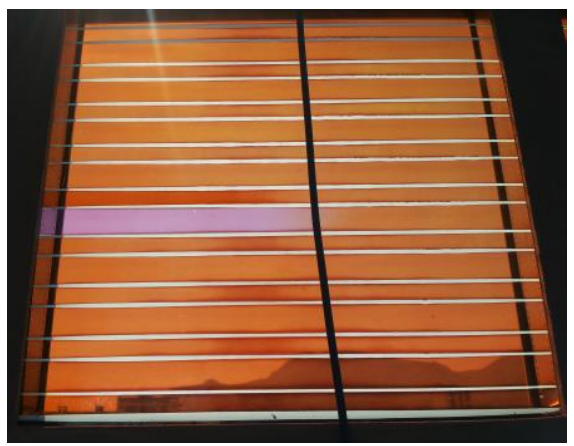

a)

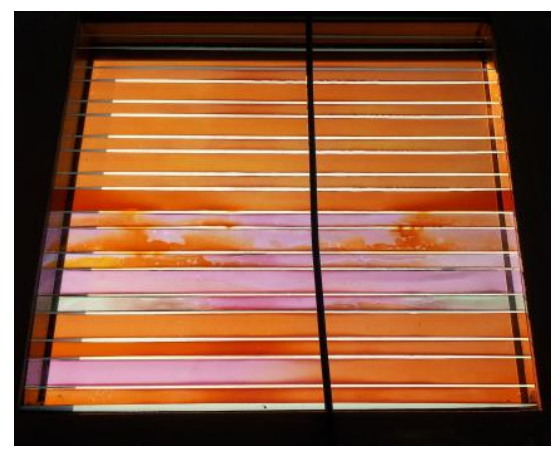

b)

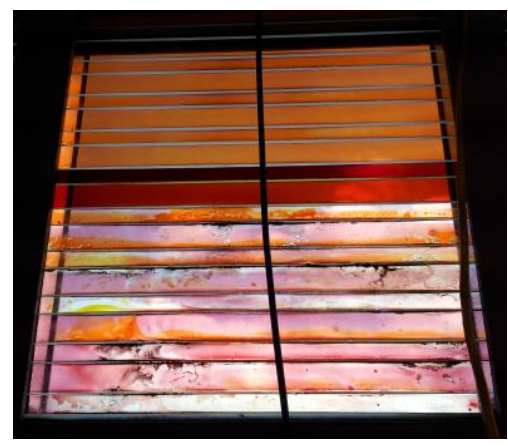

c)

Fig. 26. DSSC cells degradation during measurements: a) initial, b) during and c) finished test.. 


\section{Discussion on realization of a façade}

This section discusses the technical and economical parameters for the realization of a photovoltaic façade, both with transparent windows (3rd generation) and opaque panels (1st and 2nd generations).

It can be stated that the costs derived from the adoption of photovoltaic technologies strictly depend on the complexity of the used processes (chemicals, metallurgical or deployment layers): a-Si is a well developed technology, while DSSC just started during the third generation. Nevertheless, the process for the realization of a DSSC cell is less complicated with respect to the traditional PV panels, due to the fact simpler and minor operations have to be performed. Moreover, the energy required for high temperature processes is much lower. The only process that requires a heating of the material is the sintering process, while high temperatures are required by the processes of purification, doping, and deposition of the anti-reflective coating for the creation of a silicon cell. In addition, the process for silicon cell production is more complex due to the need of an extremely clean working environment. In this perspective, the costs for DSSCs should be much lower than those of the a-Si.

However, the production technologies required for DSSC are not fully developed in other industrial sectors, so there are no established technologies and energy-efficient process that allow reducing the payback time for any investment. From the economical point of view, the DSSC costs for their production are not easily findable

Data on the cost of production of DSSC are not easily found in the literature. Kalowekamo et al [20] have updated the information reported in [21] and [22], estimating the production costs to $2.2 \$ / \mathrm{Wp}$ [21] and $0.8 \$ / \mathrm{Wp}$ [22]. Here are reported the most interesting costs per $\mathrm{m} 2$, estimated at $64 \$ / \mathrm{m} 2(58.9 € / \mathrm{m} 2)$ for Smestad or $110.6 \$ / \mathrm{m} 2(101.7 € /$ $\mathrm{m} 2$ ) for the DSSC of Mayer, which have been calculated with the current exchange rate. Mayer suggests an efficiency of 5\% for the DSSC, whereas Smestad 25\%.

Even though the costs for the production of a polycrystalline silicon cell are quickly decreasing, a cost for innovative structure can be estimated on about $\$ 1.78$ / Wp and $267 \$ / \mathrm{m} 2(245,5 € / \mathrm{m} 2)$. For a quantitative analysis, a $1.0 \mathrm{kWp}$ wall façade has been taken into account.

Both the technical data found in literature and the values experimentally obtained. For the comparison between DSSCs, the Mayer cell has been considered since the suggested yield was closer to that obtained by the system under study. In addition, a generic opaque a-Si panel of second generation can be employed for reference test, whose cost can be defined as $1 € / \mathrm{Wp}$, or $150 € / \mathrm{m} 2$. In addition, a first generation (c-Si) panel for the façade can be considered, its cost can be the double of the a-Si one.

Table 1 shows the costs of vertical integrated systems. The cheapest system is the one created with opaque amorphous silicon panel, which cannot be used for a window. Interesting performances are given by the Mayer cell (M DSSC), whose cost is close to the traditional opaque panel. Not brilliant performances have been shown by monitored systems, whose efficiency values are far from the theoretical ones.

The use of a glass block slightly increases the costs for the realization of the system, since the yield is reduced by the shade of the frames [14].

Table 1. Comparison of the proposed systems

Experimental

Technical literature

\begin{tabular}{|c|c|c|c|c|c|}
\hline & DSSC & Blue/grey & M DSSC & $\mathrm{c}-\mathrm{Si}$ & $\mathrm{a}-\mathrm{Si}$ \\
\hline Efficiency & & & $5 \%$ & $16 \%$ & $10 \%$ \\
\hline Vertical & $0.31 \%$ & $1.31 \%$ & $2.5 \%$ & $6.4 \%$ & $4 \%$ \\
\hline Surface $\left[\mathrm{m}^{2}\right]$ & 322 & 76.6 & 40 & 17 & 25 \\
\hline Cost $[€]$ & 32806 & 18740 & 4068 & 5100 & 3750 \\
\hline Glassblock $[€]$ & 36452 & & 4520 & & \\
\hline
\end{tabular}

\section{Conclusions}

In this paper, a technical and economical analysis of the performances of solar generating façade has been presented. Two technologies have been compared: DSSC and a-Si thin film solar windows and three system were directly tested (DSSC and blue and grey solar cell). A technical evaluation of the behavior of PV walls, in terms of generated power, efficiency and Fill Factor, have been considered in different hours and days.
From the comparison of the performance of the three systems, it is noted that the silicon cells, compared to the DSSC cells, have a produced power, fill factor and efficiency higher during the morning hours. However, DSSC cells have performances comparable with a silicon cell in the afternoon hours, in the presence of scattered light.

In particular, it is observed that in case of scattered light, the performances of the DSSC improve. The DSSC is, unfortunately, subjected to degradation phenomena, leading 
to an increase of the transparency degree of the cell with obvious loss of color, even if it does not determine an excessive reduction of electrical performance of the cell.

In conclusion, the three types of cells exhibit a good degree of architectural integration in buildings, but at this moment the electrical performances in terms of power produced are far from contribute to the power requested by building in an economic form.

\section{Acknowledgements}

This work was financially supported by MIUR (Italian Ministry of Education, University and Research) and PON INext. The author thanks affectionately for their contributions Rosario Miceli, head of SDESLab (Sustainable Development and Energy Saving Laboratory of the University of Palermo) and Alessandro Busacca, head of LOOX (Laboratory of Optics and OptoelectroniX of the University of Palermo.

\section{References}

[1] EC Directive, 2010/31/EU of the European Parliament and of the Council of 19May 2010 on the Energy Performance of Buildings, 2010

[2] PasserAlexander, Ouellet-Plamondon Claudiane, Kenneally Patrick, John Viola, Habert Guillaume, The impact of future scenarios on building refurbishment strategiestowards plus energy buildings, Energy and Buildings 124 (2016) 153-163

[3] Chow Tin-tai, Li Chunying, Lin Zhang, Innovative solar windows for cooling-demand climate, Solar Energy Materials \& Solar Cells, 94 (2010) 212-220

[4] Song Jong-Hwa,An Young-Sub , Kim Soek-Ge , Lee Sung-Jin, Yoon Jong-Ho ,Choung Youn-Kyoo , Power output analysis of transparent thin-film module in building integrated photovoltaic system (BIPV), Energy and Buildings, Volume 40, Issue 11, 2008, Pages 20672075 , ISSN $0378-7788$ https://doi.org/10.1016/j.enbuild.2008.05.013.

[5] O’Reagan, B., Grätzel, M., "A low-cost, high-efficiency solar cell based on dye-sensitized colloidal TiO2 films", in Nature 353, 737 - 740 (24 October 1991); doi:10.1038/353737a0.

[6] Shukla Akash Kumar, K.Sudhakar, Prashant Baredar, A comprehensive review on design of building integrated photovoltaic system, Energy and Buildings http://dx.doi.org/10.1016/j.enbuild.2016.06.077

[7] Hinsch Andreas, Brandt Henning, Veurman Welmoed, Hemming Simon, Nittel Mathias, Würfel Uli, Putyra Piotr, Lang-Koetz Claus, Stabe Matthias, Beucker Severin , Fichter Klaus, Dye solar modules for facade applications: Recent results from project ColorSol, Solar Energy Materials and Solar Cells, Volume 93, Issues 6-7, June 2009, Pages 820-824, ISSN 09270248, https://doi.org/10.1016/j.solmat.2008.09.049

[8] Han Changwoon, Park Seungil, Oh Wonwook, Reliability-based structural optimization of $300 \times 300$ $\mathrm{mm} 2$ dye-sensitized solar cell module, Solar Energy, Volume 150, 1 July 2017, Pages 128-135, ISSN 0038092X, https://doi.org/10.1016/j.solener.2017.04.038.
[9] Lee Jae Wook, Park Jiyoung, Jung Hyung-Jo, A feasibility study on a building's window system based on dye-sensitized solar cells, Energy and Buildings 81 (2014) 38-47

[10] Skandalos Nikolaos, Karamanis Dimitris, Investigation of thermal performance of semi-transparent PV technologies, Energy and Buildings, Volume 124, 15 July 2016, Pages 19-34, ISSN 0378-7788, https://doi.org/10.1016/j.enbuild.2016.04.072.

[11] Skandalos Nikolaos, Karamanis Dimitris, PV glazing technologies, Renewable and Sustainable Energy Reviews, Volume 49, September 2015, Pages 306-322, ISSN 1364-0321, https://doi.org/10.1016/j.rser.2015.04.145.

[12] Yoon Sanghoon, Tak Sehyun, Kim Jinsoo, JunYongseok, Kang Kisuk, Park Jiyoung, Application of transparent dye-sensitized solar cells to building integrated photovoltaic systems, Building and Environment, Volume 46, Issue 10, October 2011, Pages 1899-1904, ISSN 0360-1323, https://doi.org/10.1016/j.buildenv.2011.03.010.

[13] Corrao, R., Morini, M., "Integration of Dye-Sensitized Solar Cells with Glassblock", in CZASOPISMO TECHNICZNE, Issue 3, Year 2012, p. 55-64, ISSN: 0011-4561.

[14] Viola, F ; Romano, P; Miceli, R; Riva Sanseverino, E; Corrao, R; Morini, M; Pastore. L; Pidanic, J; Perrone, G, Performance of the Glass Block in Photovoltaic Generation, 2015 Tenth International Conference on Ecological Vehicles and Renewable Energies (EVER), Monaco Ever 2015

[15] Song Jong-Hwa, Young-Sub An, Soek-Ge Kim, SungJin Lee, Jong-Ho Yoon, Youn-Kyoo Choung, Power output analysis of transparent thin-film module in building integrated photovoltaic system (BIPV), Energy and Buildings 40 (2008) 2067-2075

[16] Kwak Cheol Hwan, Baeg Je Hyun, Yang In Mo, Giribabu Krishnan, Lee Sunmook, Huh Yun Suk , Degradation analysis of dye-sensitized solar cell module consisting of 22 unit cells for thermal stability: Raman spectroscopy study, Solar Energy, Volume 130, June 2016, Pages 244-249, ISSN 0038-092X, https://doi.org/10.1016/j.solener.2016.02.017.

[17] Peng Ming, Dong Bin, Cai Xin, Wang Wei, Jiang Xiaoming, Wang Yuhong, Yang Yong, Zou Dechun, Organic dye-sensitized photovoltaic fibers, Solar Energy, Volume 150, 1 July 2017, Pages 161-165, ISSN 0038-092X, https://doi.org/10.1016/j.solener.2017.04.007.

[18] Wang Yu-Hsiang, Wong David Shan-Hill, Modelling accelerated degradation test and shelf-life prediction of dye-sensitized solar cells with different types of solvents, Solar Energy, Volume 118, August 2015, Pages 600-610, ISSN 0038-092X, https://doi.org/10.1016/j.solener.2015.05.021.

[19] Sastrawan Ronald, Dissertation on Photovoltaic modules of dye solar cells, Freiburg, 2006

[20] Kalowekamo Joseph, Baker Erin, Estimating the manufacturing cost of purely organic solar cells, Solar Energy, Volume 83, Issue 8, August 2009, Pages 1224- 
1231, ISSN 0038-092X, https://doi.org/10.1016/j.solener.2009.02.003.

[21] Meyer, T., 1996. Solid state nanocrystalline titanium oxide photovoltaic cells, These $\mathrm{N}_{-}$1542, E' cole Polytechnique Federale de Lausanne.

[22] Smestad, G., 1994. Testing of dye-sensitized TiO2 solar cells I \& II. Solar Energy Materials and Solar Cells 32, 259-272.

[23] Laustsen J., Energy Efficiency Requirements in Building Codes and Energy Efficiency Policies for New Buildings, International Energy Agency (IEA), Paris (2008)

[24] Luay N. Dwaikat, Kherun N. Ali, Green buildings cost premium: A review of empirical evidence, Energy and Buildings, Volume 110, 1 January 2016, Pages 396403, ISSN 0378-7788, https://doi.org/10.1016/j.enbuild.2015.11.021.

[25] Sanusi Yekinni Kolawole, Asafa B Tesleem, Kazeem A Akeem, "Optimization of $\mathrm{TiO} 2$ Based Henna Dye Sensitized Solar Cell using Grey-Taguchi Technique", International Journal of Renewable Energy ResearchIJRER, Vol 6, No 3 (2016), pp 1119-1128

[26] Saptadip Saha, Priyanath Das, Ajoy Kumar Chakraborty, Sharmistha Sarkar, Ruchira
Debbarma, "Fabrication of DSSC with nanoporous TiO2 film and Kenaf Hibiscus dye as sensitizer", International Journal of Renewable Energy ResearchIJRER, Vol 6, No 2 (2016), pp 620-627

[27] ATOUANI Toufik, "The Gouy-Chapman capacitor of double layer in Dye Sensitized Solar Cells: Study and simulation", Vol 6, No 1 (2016), pp 164-170

[28] Viola, F., Romano, P., Miceli, R., Spataro, C., Schettino, G., Caruso, M., Busacca, A., Parisi, A., Guarino, S., Cino, A., Comparison on the use of PV systems in the vertical walls, (2015) 2015 International Conference on Renewable Energy Research and Applications, ICRERA 2015, art. no. 7418686, pp. 1651-1653.

[29] Acciari, G., Busacca, A., Guarino, S., Imburgia, A., Madonia, A., Miceli, R., Parisi, A., Sanseverino, E.R., Romano, P., Sauba, G., Schettino, G., Spataro, C., Viola, F., "PV systems in the vertical walls: A comparison of innovative structures", 5th IEEE International Conference on Renewable Energy Research and Applications, ICRERA 2016, Article number 7884520, Pages 1185-1190. 